\title{
Contra R*- Continuous And Almost Contra R*- Continuous Functions
}

\author{
Renu Thomas* and C.Janaki** \\ *Department of Mathematics, Sree Narayana Guru College, Coimbatore (TN) INDIA. \\ * Department of Mathematics, L.R.G. Govt.Arts college for Women,Tirupur (TN) INDIA
}

\begin{abstract}
In this paper we present and study a new class of functions as a new generalization of contra continuity. Furthermore we obtain some of their basic properties and relationship with $R^{*}$-regular graphs.

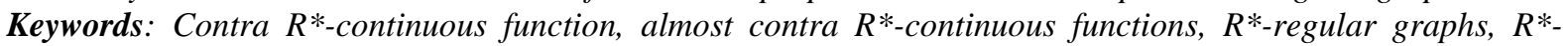
locally indiscrete.

AMS subject classification: $54 C 08,54 C 10$
\end{abstract}

\section{Introduction}

In 1996,Dontchev [5] introduced the notion of contra continuity. Several new generalizations to this class were added by Dontchev and Noiri [6] as contra-continuous functions and S-closed spaces, contra semi continuous,contra $\delta$-precontinuous functions etc. C.W.Baker [2] introduced and investigated the notion of contra $\beta$ continuity, Jafari and Noiri [11] studied the contra precontinuous and contra $\alpha$ continuous functions.

Almost contra pre continuous function was introduced by Ekici [7].In this direction we will introduce the concept of almost contra $\mathrm{R}^{*}$-continuous functions. We include the properties of contra $\mathrm{R}^{*}$-continuous functions and the $\mathrm{R}^{*}$-regular graphs.

Throughout this paper, the spaces $\mathrm{X}$ and $\mathrm{Y}$ always mean the topological spaces $(X, \tau)$ and $(Y, \sigma)$ respectively. For $\mathrm{A} \subset \mathrm{X}$, the closure and the interior of $\mathrm{A}$ in $\mathrm{X}$ are denoted by $\operatorname{cl}(\mathrm{A})$ and $\operatorname{int}(\mathrm{A})$ respectively. Also the collection of all $R^{*}$-open subsets of $X$ containing a fixed point $x$ is denoted by $R^{*}-O(X, x)$.

\section{Preliminaries}

Definition: 2.1. A subset A of a topological space $(\mathrm{X}, \tau)$ is called (1) a regular open [17] if $\mathrm{A}=\operatorname{int}(\mathrm{cl}(\mathrm{A}))$ and regular closed [17] if $\mathrm{A}=\operatorname{cl}(\operatorname{int}(\mathrm{A}))$.

The intersection of all regular closed subset of $(\mathrm{X}, \tau)$ containing $\mathrm{A}$ is called the regular closure of $\mathrm{A}$ and is denoted by $\operatorname{rcl}(\mathrm{A})$.

Definition :2.2. [4] A subset A of a space $(X, \tau)$ is called regular semi open set if there is a regular open set $U$ such that $\mathrm{U} \subset \mathrm{A} \subset \mathrm{cl}(\mathrm{U})$. The family of all regular semi open sets of $\mathrm{X}$ is denoted by $\mathrm{RSO}(\mathrm{X})$.

Lemma:2.3. [5] In a space $(X, \tau)$, the regular closed sets, regular open sets and clopen sets are regular semiopen.

Definition:2.4. A subset of a topological space $(X, \tau)$ is called

1. a regular generalized (briefly rg-closed ) [17] if $\mathrm{cl}(\mathrm{A}) \subseteq \mathrm{U}$ whenever $\mathrm{A} \subseteq \mathrm{U}$ and $\mathrm{U}$ is regular open in $\mathrm{X}$.

2. a generalized pre regular closed (briefly gpr-closed) [10] if $\operatorname{pcl}(\mathrm{A}) \subseteq \mathrm{U}$ whenever $\mathrm{A} \subseteq \mathrm{U}$ and $\mathrm{U}$ is regular open in X.

3. a regular weakly generalized closed (briefly rwg-closed) [15] if cl(int(A)) $\subseteq \mathrm{U}$ whenever $\mathrm{A} \subseteq \mathrm{U}$ and $\mathrm{U}$ is regular open in X.

4. a generalized regular closed (briefly gr-closed) [14] if $\mathrm{rcl}(\mathrm{A}) \subseteq \mathrm{U}$ whenever $\mathrm{A} \subseteq \mathrm{U}$ and $\mathrm{U}$ is open in $\mathrm{X}$.

5. a regular generalized weak closed set (briefly rgw-closed) [19] if $\operatorname{cl}(\operatorname{int}(\mathrm{A})) \subseteq \mathrm{U}$ whenever $\mathrm{A} \subseteq \mathrm{U}$ and $\mathrm{U}$ is regular semi open in $\mathrm{X}$.

The complements of the above mentioned closed sets are their respectively open sets.

Definition:2.5 [12] A subset A of a space $(X, \tau)$ is called $R^{*}$-closed if $\operatorname{rcl}(A) \subset U$ whenever $A \subset U$ and $U$ is regular semiopen in $(\mathrm{X}, \tau)$. We denote the set of all $\mathrm{R}^{*}$ - closed sets in $(\mathrm{X}, \tau)$ by $\mathrm{R} * \mathrm{C}(\mathrm{X})$.

Definition:2.6 [12]A function $f: X \rightarrow Y$ is called $\mathrm{R}^{*}$-continuous if $f^{-1}(V)$ is $\mathrm{R}^{*}$-closed in $\mathrm{X}$ for every closed set $\mathrm{V}$ of $\mathrm{Y}$.

Definition:2.7[5] A function $f: X \rightarrow Y$ is called contra continuous if $f^{-1}(V)$ is closed in $\mathrm{X}$ for every open set $\mathrm{V}$ of $\mathrm{Y}$. 
Definition:2.8 A function $f: X \rightarrow Y$ is called

1. contra rg-continuous, if $f^{-1}(V)$ is rg- closed in $\mathrm{X}$ for each open set $\mathrm{V}$ of $\mathrm{Y}$.

2. contra gpr- continuous, if $f^{-1}(V)$ is gpr- closed in $\mathrm{X}$ for each open set $\mathrm{V}$ of $\mathrm{Y}$.

3. contra rwg-continuous, if $f^{-1}(V)$ is rwg-closed in $\mathrm{X}$ for each open set $\mathrm{V}$ of $\mathrm{Y}$.

4. contra gr- continuous, if $f^{-1}(V)$ is gr- closed in $\mathrm{X}$ for each open set $\mathrm{V}$ of $\mathrm{Y}$.

5. contra rgw-continuous, if $f^{-1}(V)$ is grw- closed in $\mathrm{X}$ for each open set $\mathrm{V}$ of $\mathrm{Y}$.

6. an R-map [8] if $f^{-1}(V)$ is regular closed in $\mathrm{X}$ for each regular closed set $\mathrm{V}$ of $\mathrm{Y}$.

7. perfectly continuous if $[1,7] f^{-1}(V)$ is clopen in $\mathrm{X}$ for each open set $\mathrm{V}$ in $\mathrm{Y}$.

8. almost continuous if [20] $f^{-1}(V)$ is open in $\mathrm{X}$ for each regular open set $\mathrm{V}$ in $\mathrm{Y}$

9. regular set connected if [9] $f^{-1}(V)$ is clopen in $\mathrm{X}$ for each regular open set $\mathrm{V}$ in $\mathrm{Y}$.

10. RC-continuous [8] if $f^{-1}(V)$ is regular closed in $\mathrm{X}$ for each open set $\mathrm{V}$ in $\mathrm{Y}$.

Definition:2.9 [21] A space is said to be weakly Hausdroff if each element of $\mathrm{X}$ is an intersection of regular closed sets

Definition:2.10 [22] A space is said to be Ultra Hausdroff if for every pair of distinct points $\mathrm{x}$ and $\mathrm{y}$ in $\mathrm{X}$, there exist disjoint clopen sets $\mathrm{U}$ and $\mathrm{V}$ containing $\mathrm{x}$ and $\mathrm{y}$ respectively.

Definition:2.11[22] A topological space $X$ is called a Ultra normal space, if each pair of disjoint closed sets can be separated by disjoint clopen sets.

Definition:2.12[23] A topological space $X$ is said to be hyperconnected if every open set is dense.

\section{Contra $\mathrm{R}^{*}$-continuous functions}

Definition: 3.1 A space $\mathrm{X}$ is called locally $\mathrm{R}^{*}$-indiscrete if every $\mathrm{R}^{*}$-open subset of $\mathrm{X}$ is closed.

Definition:3.2 A function $f: X \rightarrow Y$ is called contra $\mathrm{R}^{*}$-continuous if $f^{-1}(V)$ is $\mathrm{R}^{*}$-closed in $\mathrm{X}$ for every open set $\mathrm{V}$ of $\mathrm{Y}$.

Definition :3.3 A function $f: X \rightarrow Y$ is strongly $\mathrm{R}^{*}$-open if the image of every $\mathrm{R}^{*}$-open set of $\mathrm{X}$ is $\mathrm{R}^{*}$-open in Y.

Definition :3.4 A function $f: X \rightarrow Y$ is almost $\mathrm{R}^{*}$-continuous if $f^{-1}(V)$ is $\mathrm{R}^{*}$-open in $\mathrm{X}$ for each regular open set $\mathrm{V}$ of $\mathrm{Y}$.

Theorem:3.5 Every contra $\mathrm{R}^{*}$-continuous function is contra rg-continuous, contra gpr-continuous, contra rwgcontinuous, contra gr-continuous, contra rgw-continuous but not conversely.

Proof :Obvious from definitions.

Example

3.6:

Let

$$
X=\{a, b, c, d\}=Y, \tau=\{X, \phi,\{b\},\{d\},\{b, d\},\{a, b, d\},\{b, c, d\}\} \sigma=\{Y, \phi,\{a\},\{c\},\{a, c\},\{c, d\},\{a, c, d\}\}
$$

Define a mapping $f: X \rightarrow Y$ as the identity mapping. Here the function $\mathrm{f}$ is contra rg-continuous, contra gprcontinuous and contra rwg- continuous but not contra $\mathrm{R}^{*}$-continuous since $f^{-1}\{a\}=a a n d f^{-1}\{c\}=c$ are not $\mathrm{R}^{*}$-closed.

Example

$X=\{a, b, c, d\}=Y, \tau=\{X, \phi,\{a\},\{b\},\{a, b\},\{a, b, c\}\}, \sigma=\{Y, \phi,\{b\},\{a, b\},\{b, c\},\{a, b, c\}\}$.

Define a mapping $f: X \rightarrow Y$ as $f(a)=c, f(b)=a, f(c)=d, f(d)=b$, the function $\mathrm{f}$ is contra grcontinuous but not contra $\mathrm{R} *$-continuous.

Example3.8:

$X=\{a, b, c, d\}=Y, \tau=\{X, \phi,\{a\},\{d\},\{a, d\},\{a, b\},\{a, b, d\}\}, \sigma=\{Y, \phi,\{c, d\},\{a, c, d\}\}$.

Define a mapping $f: X \rightarrow Y$ as $f(a)=b, f(b)=a, f(c)=d, f(d)=c$, the function $\mathrm{f}$ is contra rgwcontinuous but not contra $\mathrm{R} *$-continuous.

Remark:3.9

Contra continuous and contra $\mathrm{R}^{*}$-continuous are independent concepts. 


\section{Example:3.10}

Let $\mathrm{X}=\mathrm{Y}=\{\mathrm{a}, \mathrm{b}, \mathrm{c}\} \tau=\{X, \phi,\{a\},\{b, c\}\} \quad \sigma=\{Y, \phi,\{b\},\{c\},\{b, c\}\} \mathrm{R}^{*-\mathrm{C}}(\mathrm{X})=$ set of all subsets of $\left.\mathrm{X}\right\}$.

Define $\mathrm{f}: \mathrm{X} \rightarrow \mathrm{Y}$ as the identity mapping .Here $\mathrm{f}$ is contra $\mathrm{R}^{*}$-continuous but not contra continuous since $f^{-1}\{b\}=\{b\}$ is not closed in X.

Example 3.11: Let $\mathrm{X}=\mathrm{Y}=\{\mathrm{a}, \mathrm{b}, \mathrm{c}, \mathrm{d}\} \quad \tau=\{X, \phi,\{a\},\{b\},\{a, b\},\{a, b, c\}\} \quad \sigma=\{Y, \phi,\{d\}\}$

$R^{*}-C(X)=\{X, \phi,\{a, b\},\{c, d\},\{a, b, c\},\{a, b, d\},\{a, c, d\},\{b, c, d\}\}$. Define $\mathrm{f}: \mathrm{X} \rightarrow \mathrm{Y}$ as the identity mapping. $f^{-1}\{d\}=\{d\}$ is not $\mathrm{R}^{*}$-closed and hence is not contra $\mathrm{R}^{*}$-continuous but contra continuous.

Theorem3.12: Every RC continuous function is contra $\mathrm{R} *$-continuous but not conversely.

Proof : Straight forward.

Example 3.13: Let $X=Y=\{a, b, c\} \tau=\{\{X\},\{\phi\},\{a\},\{b\},\{a, b\}\}, \sigma=\{Y, \phi,\{a\},\{a, b\},\{a, c\}\}$

Define $f: X \rightarrow Y$ as $\quad f(a)=b, f(b)=c, f(c)=a$

Here $\mathrm{f}$ is contra $\mathrm{R}^{*}$-continuous but not $\mathrm{RC}$-continuous.

Remark 3.14:

The composition of two contra $\mathrm{R}^{*}$-continuous functions need not be contra $\mathrm{R}^{*}$-continuous as seen in the following example.

Example3.15: let $\mathrm{X}=\mathrm{Y}=\mathrm{Z}=\{\mathrm{a}, \mathrm{b}, \mathrm{c}\} \quad \tau=\{\mathrm{X}, \phi,\{\mathrm{a}\},\{\mathrm{c}\},\{\mathrm{a}, \mathrm{c}\}\} \quad \sigma=\{\mathrm{Y}, \phi,\{\mathrm{a}, \mathrm{b}\}\}$

$\eta=\{Z, \phi,\{b\},\{a, c\}\} \quad R^{*}-C(X)=\{X, \phi,\{b\},\{a, b\},\{b, c\},\{c, a\}\}$

$\mathrm{R}^{*}-\mathrm{C}(\mathrm{Y})=\{\mathrm{X}, \phi,\{\mathrm{a}\},\{\mathrm{b}\},\{\mathrm{c}\},\{\mathrm{a}, \mathrm{b}\},\{\mathrm{b}, \mathrm{c}\},\{\mathrm{c}, \mathrm{a}\}\}$

Define $\mathrm{f}: \mathrm{X} \rightarrow \mathrm{Y}$ by $\mathrm{f}(\mathrm{a})=\mathrm{b}, \mathrm{f}(\mathrm{b})=\mathrm{c}, \mathrm{f}(\mathrm{c})=\mathrm{a}, \mathrm{g}: \mathrm{Y} \rightarrow \mathrm{Z}$ by $\mathrm{g}(\mathrm{a})=\mathrm{b}, \mathrm{g}(\mathrm{b})=\mathrm{c}$, and $\mathrm{g}(\mathrm{c})=\mathrm{a}$,

Then $f$ and $g$ are contra $R^{*}$-continuous but $g \circ f: X \rightarrow Z$ is not contra $R^{*}$-continuous since $(g \circ f)^{-1}\{b\}=f^{-1}\left(g^{-1}\{b\}\right)=f^{-1}(a)=\{c\}$ is not $R^{*}$-closed .

Theorem3.16: If $\mathrm{f}:(\mathrm{X}, \tau) \rightarrow(\mathrm{Y}, \sigma)$ is a contra $\mathrm{R}^{*}$-continuous function and $\mathrm{g}:(\mathrm{Y}, \sigma) \rightarrow(\mathrm{Z}, \mathrm{\eta})$ is a continuous function, then the function $\mathrm{g} \circ \mathrm{f}: \mathrm{X} \rightarrow \mathrm{Z}$ is contra $\mathrm{R}^{*}$-continuous.

Proof: Let $V$ be open in Z. Since $g$ is continuous, $g^{-1}(V)$ is open in Y.f is contra $R^{*}$-continuous,so $f^{-1}\left(g^{-1}(V)\right.$ is $\mathrm{R}^{*}$-closed in $\mathrm{X}$. Hence $(\mathrm{g} \circ \mathrm{f})^{-1}(\mathrm{~V})$ is $\mathrm{R}^{*}$-closed in $\mathrm{X}$. i.e $\mathrm{g} \circ \mathrm{f}$ is contra $\mathrm{R}^{*}$-continuous.

Theorem 3.17: If $\mathrm{f}:(\mathrm{X}, \tau) \rightarrow(\mathrm{Y}, \sigma)$ is a contra $\mathrm{R}^{*}$-continuous map and $\mathrm{g}:(\mathrm{Y}, \sigma) \rightarrow(\mathrm{Z}, \eta)$ is regular set connected function, then $\mathrm{g} \circ \mathrm{f}: \mathrm{X} \rightarrow \mathrm{Z}$ is $\mathrm{R}^{*}$-continuous and almost $\mathrm{R}^{*}$-continuous.

Proof: Let $\mathrm{V}$ be regular open in Z.Since $\mathrm{g}$ is regular set connected, $\mathrm{g}^{-1}(\mathrm{~V})$ is clopen in $\mathrm{Y}$. Since $\mathrm{f}$ is a contra $\mathrm{R}^{*}$-continuous $\mathrm{f}^{-1}\left(\mathrm{~g}^{-1}(\mathrm{~V})\right.$ is $\mathrm{R}^{*}$-closed in $\mathrm{X}$ Hence $\mathrm{g} \circ \mathrm{f}$ is almost $\mathrm{R}^{*}$-continuous.

Theorem 3.18: If $\mathrm{f}:(\mathrm{X}, \tau) \rightarrow(\mathrm{Y}, \sigma)$ is $\mathrm{R}^{*}$ - irresolute and $\mathrm{g}:(\mathrm{Y}, \sigma) \rightarrow(\mathrm{Z}, \eta)$ is a contra $\mathrm{R}^{*}$ - continuous function ,then $\mathrm{g} \circ \mathrm{f:X} \rightarrow \mathrm{Z}$ is contra $\mathrm{R}^{*}$-continuous.

Proof: Let $\mathrm{V}$ be open in $\mathrm{Z}$. Since $g$ is contra $R^{*}$-continuous, $g^{-1}(V)$ is $R^{*}$-closed in $Y$. Since $f$ is a contra $R^{*}$-irresolute, $f^{-1}\left(g^{-1}(V)\right.$ is $R^{*}$-closed in $X$. Hence $g \circ f$ is contra $R^{*}$-continuous.

Theorem3.19: If $f:(X, \tau) \rightarrow(Y, \sigma)$ is $R^{*}$ - continuous and the space $X$ is $R^{*}$-locally indiscrete, then $f$ is contra continuous.

Proof : Let $\mathrm{V}$ be an open set in $\mathrm{Y}$. Since $\mathrm{f}$ is $\mathrm{R}^{*}$-continuous $f^{-1}(V)$ is $\mathrm{R}^{*}$ - open in $\mathrm{X}$. And since $\mathrm{X}$ is locally $\mathrm{R}^{*}$-indiscrete, $f^{-1}(V)$ is closed in $\mathrm{X}$. Hence $\mathrm{f}$ is contra continuous.

Theorem 3.20: If $\mathrm{f}:(\mathrm{X}, \tau) \rightarrow(\mathrm{Y}, \sigma)$ is contra $\mathrm{R}^{*}$-continuous, $\mathrm{X}$ is $\mathrm{R}^{*}-\mathrm{T}_{1 / 2}$ space, then $\mathrm{f}$ is $\mathrm{RC}$-continuous.

Proof : Let $\mathrm{V}$ be open in $\mathrm{Y}$. Since $\mathrm{f}$ is contra $\mathrm{R}^{*}$ - continuous, $f^{-1}(V)$ is $\mathrm{R}^{*}$-closed in $\mathrm{X}$. And $\mathrm{X}$ is $\mathrm{R}^{*}-\mathrm{T}_{1 / 2}$ space, hence $f^{-1}(V)$ is regular closed in $\mathrm{X}$. Thus for every open set $\mathrm{V}$ of $\mathrm{Y}, f^{-1}(V)$ is regular closed in $\mathrm{X}$. Hence $\mathrm{f}$ is RC-continuous.

Theorem3.21: Suppose $\mathrm{R}^{*} \mathrm{O}(\mathrm{X})$ is closed under arbitrary unions ,then the following are equivalent for a function $\mathrm{f}:(\mathrm{X}, \tau) \rightarrow(\mathrm{Y}, \sigma)$,

(i) $\quad \mathrm{f}$ is contra $\mathrm{R}^{*}$-continuous

(ii) for every closed subset $\mathrm{V}$ of $\mathrm{Y}, f^{-1}(V) \in \mathrm{R}^{*}-\mathrm{O}(\mathrm{X})$.

(iii) for each $x \in X$ and each $V \in C(Y, f(x))$,there exists a set $U \in R^{*} O(X, x)$ such that $f(U) \subset V$. 
Proof : (i) $\Rightarrow$ (ii): Let $\mathrm{f}$ be contra $\mathrm{R}^{*}$ - continuous. Then $f^{-1}(V)$ is $\mathrm{R} *$-closed in $\mathrm{X}$ for every open set $\mathrm{V}$ of $\mathrm{Y}$. i.e $f^{-1}(V)$ is $\mathrm{R}^{*}$-open in $\mathrm{X}$ for every closed set $V$ of $\mathrm{Y}$. Hence $f^{-1}(V) \in R^{*}-O(X)$.

(ii) $\Rightarrow$ (i) :Obvious.

(ii) $\Rightarrow$ (iii) : For every closed subset $\mathrm{V}$ of $\mathrm{Y}, f^{-1}(V) \in \mathrm{R}^{*}-\mathrm{O}(\mathrm{X})$. Then for each $\mathrm{x} \in \mathrm{X}$ and each $V \in C(Y, f(x))$, there exists a set $\mathrm{U} \in R^{*}-O(X)$ such that $f(U) \subset V$.

(iii) $\Rightarrow$ (ii) : For each $x \in X$ and each $V \in C(Y, f(x))$,there exists a set $U_{x} \in R^{*}-O(X, x)$ such that $f\left(U_{x}\right) \subset V$.i.e $x \in f^{-1}(V)$ and $f(x) \subset V$. So there exists $U \in R^{*}-O(X, x)$ such that $f^{-1}(V)=$ $\cup\left\{U_{x}: x \in f^{-1}(V)\right\}$ and Hence $f^{-1}(V)$ is $\mathrm{R}^{*}$-open.

Definition 3.22:[7] For a function $\mathrm{f}: \mathrm{X} \rightarrow \mathrm{Y}$, the subset $\{(x, f(x)): x \in X\} \subset X \times Y$ is called the graph of $\mathrm{f}$ and is denoted by $\mathrm{G}(\mathrm{f})$.

Lemma 3.23: [3] Let $\mathrm{G}(\mathrm{f})$ be the graph of $\mathrm{f}$, for any subset $A \subset X$ and $B \subset Y$, we have $f(A) \cap B=\varphi$ if and only if $(A \times B) \cap G(f)=\varphi$.

Definition 3.24: The graph $\mathrm{G}(\mathrm{f})$ of a function $\mathrm{f}: \mathrm{X} \rightarrow \mathrm{Y}$ is said to be contra $\mathrm{R}^{*}$-closed if for each $(\mathrm{x}, \mathrm{y})$ $\in(X, Y)-G((f))$ there exists $U \in R^{*} O(X, x)$ and $V \in C(Y, y)$ such that $(U \times V) \cap G(f)=\varphi$.

Lemma 3.25: The graph $\mathrm{G}(\mathrm{f})$ of a function $\mathrm{f}: \mathrm{X} \rightarrow \mathrm{Y}$ is said to be contra $\mathrm{R}^{*}$-closed if for each $(\mathrm{x}, \mathrm{y})$ $\in(X, Y)-G((f))$ there exists $U \in R^{*} O(X, x)$ and $V \in C(Y, y)$ such that $f(U) \cap V=\varphi$.

Proof: The proof is a direct consequence of definition 3.24 and lemma.3.23

\section{Almost contra $\mathbf{R}^{*}$-continuous function}

Definition 4.1: A function $f: \mathrm{X} \rightarrow \mathrm{Y}$ is said to be almost contra $\mathrm{R}^{*}$-continuous is $f^{-1}$ is $\mathrm{R}^{*}$-closed in $\mathrm{X}$ for each regular open set $\mathrm{V}$ in $\mathrm{Y}$.

Theorem 4.2: If a function $\mathrm{f}: \mathrm{X} \rightarrow \mathrm{Y}$ is almost contra $\mathrm{R}^{*}$-continuous and $\mathrm{X}$ is locally $\mathrm{R}$ *-indiscreet space, then $\mathrm{f}$ is almost continuous.

Proof: Let $\mathrm{U}$ be regular open set in $\mathrm{Y}$. Since $\mathrm{f}$ is almost contra $\mathrm{R}^{*}$-continuous $\mathrm{f}^{-1}(\mathrm{U})$ is $\mathrm{R}^{*}$-closed set in $\mathrm{X}$ and $\mathrm{X}$ is locally $\mathrm{R}^{*}$-indiscreet space, which implies $\mathrm{f}^{-1}(\mathrm{U})$ is an open set in $\mathrm{X}$. Therefore $\mathrm{f}$ is almost continuous.

Theorem 4.3: If a function $\mathrm{f}: \mathrm{X} \rightarrow \mathrm{Y}$ is contra $\mathrm{R}^{*}$-continuous, then it is almost contra $\mathrm{R}^{*}$-continuous.

Proof: Obvious because every regular open set is open set.

Remark 4.4: The converse of the theorem need not be true in general as seen from the following example.

$\mathrm{X}=\{\mathrm{a}, \mathrm{b}, \mathrm{c}\}=\mathrm{Y}, \quad \tau=\{\mathrm{X}, \phi,\{\mathrm{a}\},\{\mathrm{b}\},\{\mathrm{a}, \mathrm{b}\}\} \quad \sigma \quad=\{\quad \mathrm{X}, \phi,\{\mathrm{a}\},\{\mathrm{b}\},\{\mathrm{ab}\},\{\mathrm{b}, \mathrm{c}\}\}$

$\mathrm{R}^{*} \mathrm{C}(\mathrm{X})=\{\mathrm{X}, \phi,\{\mathrm{c}\},\{\mathrm{ab}\},\{\mathrm{b}, \mathrm{c}\},\{\mathrm{c}, \mathrm{a}\}\}$.Define $\mathrm{f}(\mathrm{c})=\mathrm{a}, \mathrm{f}(\mathrm{a})=\mathrm{b}, \mathrm{f}(\mathrm{b})=\mathrm{c}$, $\mathrm{f}^{-1}(\{\mathrm{~b}\})=\{\mathrm{a}\}$ which is not $\mathrm{R}^{*}$-closed in $\mathrm{X}$.

Theorem 4.5: The following are equivalent for a function $\mathrm{f}: \mathrm{X} \rightarrow \mathrm{Y}$

1. $\mathrm{f}$ is almost contra $\mathrm{R}^{*}$ - continuous

2. for every regular closed set $\mathrm{F}$ of $\mathrm{Y}, \mathrm{f}^{-1}(\mathrm{~F})$ is $\mathrm{R}^{*}$-open set of $\mathrm{X}$.

Proof: (i) Let $\mathrm{F}$ be a regular closed set in $\mathrm{Y}$, then $\mathrm{Y}-\mathrm{F}$ is a regular open set in $\mathrm{Y}$. By

(i) $\mathrm{f}^{-1}(\mathrm{Y}-\mathrm{F})=\mathrm{X}-\mathrm{f}^{-1}(\mathrm{~F})$ is $\mathrm{R}^{*}$-closed in $\mathrm{X}$. Therefore (ii) holds.

(ii) $\Rightarrow$ (i). Let $G$ be a regular open set in $Y$. Then $Y-G$ is regular closed in $Y$. By (ii) $f^{-1}(Y-G)$ is an $R^{*}$-open set in $X$. This implies $X-f^{-1}(G)$ is $R^{*}$-open which implies, $f^{-1}(G)$ is $R^{*}$-closed set in $X$. Therefore (i) holds.

Theorem 4.6: The following are equivalent for a function $\mathrm{f}: \mathrm{X} \rightarrow \mathrm{Y}$

1. $f$ is almost contra $\mathbf{R}^{*}$-continuous.

2. $f^{-1}(\operatorname{int}(\operatorname{cl}(G)))$ is a $\mathrm{R}^{*}$-closed set in $\mathrm{X}$ for every open set $\mathrm{G}$ of $\mathrm{Y}$.

3. $f^{-1}(c l(\operatorname{int}(F)))$ is a $\mathrm{R}^{*}$-open set in $\mathrm{X}$ for every open subset $\mathrm{F}$ of $\mathrm{Y}$.

Proof: (i) $\Rightarrow$ (ii).Let $\mathrm{G}$ be an open set in Y. Then int $(\mathrm{cl}(\mathrm{G}))$ is regular open set in Y. By (i) $f^{-1}(\operatorname{int}(\operatorname{cl}(G))) \in$ $\mathrm{R}^{*}-\mathrm{C}(\mathrm{X})$.

(ii) ) $\Rightarrow$ (i). Proof is obvious. 
(i) $\Rightarrow$ (iii).Let $\mathrm{F}$ be a closed set in $\mathrm{Y}$. Then $\operatorname{cl}(\operatorname{int}(\mathrm{F}))$ is a regular closed set in Y. By (i) $f^{-1}(\operatorname{cl}(\operatorname{int}(F))) \in$ $\mathrm{R}^{*}-\mathrm{O}(\mathrm{X})$.

(iii) $\Rightarrow$ (i).Proof is obvious.

Definition 4.7: A space $X$ is said to be

1. $\mathrm{R}^{*}-\mathrm{T}_{1 / 2}$ space $[13]$ if every $\mathrm{R}^{*}$-closed set is regular closed.

2. $\mathrm{R}^{*}-\mathrm{T}_{0}$ if for each pair of distinct points in $\mathrm{X}$, there is an $\mathrm{R}^{*}$-open set of $\mathrm{X}$ containing one point but not the other.

3. $\mathrm{R}^{*}-\mathrm{T}_{1}$ if for every pair of distinct points $\mathrm{x}$ and $\mathrm{y}$,there exists $\mathrm{R}^{*}$-open sets $\mathrm{G}$ and $\mathrm{H}$ such that $x \in G, y \notin G a n d x \notin H, y \in H$.

4. $\mathrm{R}^{*}-\mathrm{T}_{2}$ if for every pair of distinct points $\mathrm{x}$ and $\mathrm{y}$, there exists disjoint $\mathrm{R}^{*}$-open sets $\mathrm{G}$ and $\mathrm{H}$ such that $x \in G a n d y \in H$.

Theorem 4.8: If $\mathrm{f}: \mathrm{X} \rightarrow \mathrm{Y}$ is an almost contra $\mathrm{R}^{*}$-continuous injection and $\mathrm{Y}$ is weakly Hausdroff then $\mathrm{X}$ is $\mathrm{R}^{*}$ $\mathrm{T}_{1}$.

Proof: Suppose $\mathrm{Y}$ is weakly Hausdroff, for any distinct points $\mathrm{x}$ and $\mathrm{y}$ in $\mathrm{X}$, there exists $\mathrm{V}$ and $\mathrm{W}$ regular closed sets in $\mathrm{Y}$ such that $f(x) \in V, f(y) \notin \operatorname{Vand} f(y) \in \operatorname{Wand} f(x) \notin W$. Since $\mathrm{f}$ is almost contra $\mathrm{R}^{*}$ continuous $f^{-1}(V)$ and $f^{-1}(W)$ are $\mathrm{R}^{*}$-open subsets of $\mathrm{X}$ such that $x \in f^{-1}(V), y \notin f^{-1}(V), y \in f^{-1}(W)$ and $x \notin f^{-1}(W)$.This shows that $\mathrm{X}$ is $\mathrm{R}^{*}-\mathrm{T}_{1}$. Corollary 4.9: If $\mathrm{f:}(\mathrm{X}, \tau) \rightarrow(\mathrm{Y}, \sigma)$ is a contra $\mathrm{R}^{*}$-continuous injection and $\mathrm{Y}$ is weakly Hausdroff, then $\mathrm{X}$ is $\mathrm{R}^{*}$ $\mathrm{T}_{1}$.

Proof: Every contra $\mathrm{R}^{*}$-continuous is almost contra $\mathrm{R}^{*}$-continuous and by the above theorem [4.8] the result follows.

Theorem:4.10 If $\mathrm{f}: \mathrm{X} \rightarrow \mathrm{Y}$ is an almost contra $\mathrm{R}^{*}$-continuous injective function from a space $\mathrm{X}$ into the Ultra Haudroff space $\mathrm{Y}$, then $\mathrm{Y}$ is an $\mathrm{R}^{*}-\mathrm{T}_{2}$. Proof: Let $\mathrm{x}$ and $\mathrm{y}$ be any two distinct points in $\mathrm{X}$. Since $\mathrm{f}$ is an injective function such that $\mathrm{f}(\mathrm{x}) \neq \mathrm{f}(\mathrm{y})$ and $\mathrm{Y}$ is Ultra Hausdorff space, there exists disjoint clopen sets $\mathrm{U}$ and $\mathrm{V}$ containing $\mathrm{f}(\mathrm{x})$ and $\mathrm{f}(\mathrm{y})$ respectively. Then $\mathrm{x} \in f^{-1}(\mathrm{U})$ and $y \in f^{-1}(\mathrm{~V})$, were $f^{-1}(\mathrm{U})$ and $f^{-1}(\mathrm{~V})$ are disjoint $\mathrm{R}^{*}$ - open sets in $\mathrm{X}$. Therefore $\mathrm{Y}$ is $\mathrm{R} *-\mathrm{T}_{2}$.

Definition:4.11 A topological space $\mathrm{X}$ is called a $\mathrm{R}^{*}$ - normal space, if each pair of disjoint closed sets can be separated by disjoint $\mathrm{R}^{*}$-open sets. Theorem:4.12 If $\mathrm{f}: \mathrm{X} \rightarrow \mathrm{Y}$ is an almost contra $\mathrm{R}^{*}$-continuous, closed, injective function and $\mathrm{Y}$ is Ultra Normal, then $\mathrm{X}$ is $\mathrm{R} *$-normal.

Proof: Let $E$ and $F$ be disjoint closed subsets of $X$. Since $f$ is closed and injective $f(E)$ and $f(F)$ are disjoint closed sets in $Y$. Since $Y$ is ultra normal there exists disjoint clopen sets in $U$ and $V$ in $Y$ such that $f(E) \subset U$ and $\mathrm{f}(\mathrm{F}) \subset \mathrm{V}$.This implies $\mathrm{E} \subset f^{-1}(\mathrm{U})$ and $\mathrm{F} \subset f^{-1}(\mathrm{~V})$.Since $\mathrm{f}$ is an almost contra $\mathrm{R}^{*}$-continuous injection $f^{-1}(\mathrm{U})$ and $f^{-1}(\mathrm{~V})$ are disjoint $\mathrm{R}^{*}$-open sets in $\mathrm{X}$.This show that $\mathrm{X}$ is $\mathrm{R}^{*}$-normal.

Theorem:4.13 For two functions $\mathrm{f}: \mathrm{X} \rightarrow \mathrm{Y}$ and $\mathrm{k}: \mathrm{Y} \rightarrow \mathrm{Z}$, let $\mathrm{k} \circ f: \mathrm{X} \rightarrow \mathrm{Z}$ is a composition function. Then the following holds:

(1) If $\mathrm{f}$ is almost contra $\mathrm{R}^{*}$-continuous and $\mathrm{k}$ is an $\mathrm{R}$-map, then $k \circ f$ is almost contra $\mathrm{R}^{*}$-continuous.

(2) If $\mathrm{f}$ is almost contra $\mathrm{R}^{*}$-continuous and $\mathrm{k}$ is perfectly continuous, then $k \circ f$ is $\mathrm{R}^{*}$-continuous and contra $R^{*}$-continuous.

(3) If $\mathrm{f}$ is almost contra $\mathrm{R}^{*}$-continuous and $\mathrm{k}$ is almost continuous, then $k \circ f$ is almost contra $\mathrm{R}^{*}$ continuous.

Proof: (1) Let $\mathrm{V}$ be any regular open set in $\mathrm{Z}$. Since $\mathrm{k}$ is an $\mathrm{R}$-map, $\mathrm{k}^{-1}(\mathrm{~V})$ is regular open in $\mathrm{Y}$. Since $\mathrm{f}$ is almost contra $\mathrm{R}^{*}$ - continuous $f^{-1}\left(k^{-1}(V)\right)=(k \circ f)^{-1}(\mathrm{~V})$ is $\mathrm{R}^{*}$-closed in $\mathrm{X}$. Therefore $k \circ f$ is almost contra $\mathrm{R}^{*}$ continuous.

(2) Let $\mathrm{V}$ be an open set in Z. Since $\mathrm{k}$ is perfectly continuous, $k^{-1}(V)$ is clopen in Y.Since $\mathrm{f}$ is an almost contra $\mathrm{R}^{*}$ - continuous $f^{-1}\left(k^{-1}(V)\right)=(k \circ f)^{-1}(\mathrm{~V})$ is $\mathrm{R}^{*}$-open and $\mathrm{R}^{*}$-closed set in $\mathrm{X}$. Therefore $\mathrm{k} \circ f$ is $\mathrm{R}^{*}$ continuous and contra $\mathrm{R}^{*}$ - continuous.

(3) Let $\mathrm{V}$ be a regular open set in $\mathrm{Z}$. Since $\mathrm{k}$ is almost continuous, $k^{-1}(V)$ is open in $\mathrm{Y}$. Since $\mathrm{f}$ is contra $\mathrm{R}^{*}$ continuous $f^{-1}\left(k^{-1}(V)\right)=(k \circ f)^{-1}(\mathrm{~V})$ is $\mathrm{R}^{*}$-closed in $\mathrm{X}$. Therefore $\mathrm{k} \circ f$ is almost contra $\mathrm{R}^{*}$-continuous.

Theorem:4.14 Let $\mathrm{f}: \mathrm{X} \rightarrow \mathrm{Y}$ is a contra $\mathrm{R}^{*}$-continuous function and $\mathrm{g}: \mathrm{Y} \rightarrow \mathrm{Z}$ is $\mathrm{R}^{*}$-continuous.If $\mathrm{Y}$ is $\mathrm{R}^{*}-\mathrm{T}_{1 / 2}$ ,then $g \circ f: X \rightarrow Z$ is an almost contra $\mathrm{R}^{*}$-continuous function . 
Proof: Let V be regular open and hence open set in $\mathrm{Z}$. Since $\mathrm{g}$ is $\mathrm{R}^{*}$-continuous $g^{-1}(V)$ is $\mathrm{R}^{*}$ - open in $\mathrm{Y}$ and $\mathrm{Y}$ is $\mathrm{T}_{1 / 2}$-space implies $\mathrm{g}^{-1}(\mathrm{~V})$ is regular open in $\mathrm{Y}$. Since $\mathrm{f}$ is almost contra $\mathrm{R}^{*}$ - continuous $f^{-1}\left(g^{-1}(V)\right)=(g \circ f)^{-1}(V)$ is $\mathrm{R}^{*}$-closed set in X. Therefore $g \circ f$ is almost contra $\mathrm{R}^{*}$-continuous.

Theorem:4.15 If $\mathrm{f}: \mathrm{X} \rightarrow \mathrm{Y}$ is surjective, strongly $\mathrm{R}^{*}$-open (or strongly $\mathrm{R}^{*}$-closed) and $\mathrm{g}: \mathrm{Y} \rightarrow \mathrm{Z}$ is a function such that $g \circ f: X \rightarrow Z$ is almost contra $\mathrm{R}^{*}$ - continuous, then $\mathrm{g}$ is almost contra continuous.

Proof: Let $\mathrm{V}$ be any regular closed set (resp regular open) set in $\mathrm{Z}$. Since $g \circ f$ is almost contra $\mathrm{R}^{*}$-continuous $(g \circ f)^{-1}(V)=f^{-1}\left(g^{-1}(V)\right)$ is $\mathrm{R}^{*}$-open (resp $\mathrm{R}^{*}$-closed) in $\mathrm{X}$.Since $\mathrm{f}$ is surjective and strongly $\mathrm{R}^{*}$-open (or strongly $\mathrm{R}^{*}$-closed). $f\left(f^{-1}\left(g^{-1}(V)\right)\right)=g^{-1}(V)$ is $\mathrm{R}^{*}$-open (resp $\mathrm{R}^{*}$-closed).Therefore $\mathrm{g}$ is almost contra $\mathrm{R}^{*}$-continuous.

Definition:4.16 A topological space $\mathrm{X}$ is said to be $\mathrm{R}^{*}$-ultra connected if every two non empty $\mathrm{R}^{*}$-closed subsets of $\mathrm{X}$ intersect.

Theorem:4.17 If $\mathrm{X}$ is $\mathrm{R}^{*}$-ultra connected and $\mathrm{f}: \mathrm{X} \rightarrow \mathrm{Y}$ is an almost contra $\mathrm{R}^{*}$-continuous surjection ,then $\mathrm{Y}$ is hyperconnected.

Proof: Let $\mathrm{X}$ be $\mathrm{R}^{*}$-ultraconnected and $\mathrm{f}: \mathrm{X} \rightarrow \mathrm{Y}$ is an almost contra $\mathrm{R}^{*}$-continuous surjection. Suppose $\mathrm{Y}$ is not hyperconnected. Then there is an open set $\mathrm{V}$ such that $\mathrm{V}$ is not dense in $\mathrm{Y}$. Therefore there exists non empty regular open subsets $\mathrm{B}_{1}=\operatorname{intcl}(\mathrm{V})$ and $\mathrm{B}_{2}=\mathrm{Y}-\mathrm{cl}(\mathrm{V})$ in $\mathrm{Y}$. Since $\mathrm{f}$ is an almost contra $\mathrm{R}^{*}$-continuous surjection, $f^{-1}\left(B_{1}\right)$ and $f^{-1}\left(B_{2}\right)$ are disjoint $\mathrm{R}^{*}$-closed sets in $\mathrm{X}$.This is contrary to the fact that $\mathrm{X}$ is $\mathrm{R}^{*}$-ultra connected .Therefore $\mathrm{Y}$ is hyperconnected.

\section{V. $\quad \mathbf{R}^{*}$-Regular graphs}

Definition 5.1: A graph $\mathrm{G}(\mathrm{f})$ of a function $\mathrm{f}: \mathrm{X} \rightarrow \mathrm{Y}$ is said to be $\mathrm{R}^{*}$-regular if for each $(\mathrm{x}, \mathrm{y}) \in(X, Y)-G((f)) \quad$ there $\quad$ exists $U \in R^{*} C(X, x)$ and $V \in R O(Y, y)$ such $\quad$ that $(U \times V) \cap G(f)=\varphi$.

Lemma 5.2: The graph $\mathrm{G}(\mathrm{f})$ of a function $\mathrm{f}: \mathrm{X} \rightarrow \mathrm{Y}$ is $\mathrm{R}^{*}$-regular (resp strong contra $\mathrm{R}^{*}$ closed) in $X \times Y$ if and only if for each $(\mathrm{x}, \mathrm{y}) \in(X, Y)-G((f))$, there is an $\mathrm{R}^{*}$-closed (resp $\mathrm{R}^{*}$-open) set $\mathrm{U}$ in $\mathrm{X}$ containing $\mathrm{x}$ and $V \in R O(Y, y)(\operatorname{resp} V \in R C(Y, y))$ such that $f(U) \cap V=\phi$.

Proof: Obvious.

Theorem 5.3: If a function $\mathrm{f}: \mathrm{X} \rightarrow \mathrm{Y}$ is almost $\mathrm{R}^{*}$-continuous and $\mathrm{Y}$ is $\mathrm{T}_{2}$ then $\mathrm{G}(\mathrm{f})$ is $\mathrm{R}^{*}$-regular in $X \times Y$. Proof: Let $(x, y) \in(X, Y)-G(f)$. Then $y \neq f(x)$. Since $\mathrm{Y}$ is $\mathrm{T}_{2}$, there exists open set $\mathrm{V}$ and $\mathrm{W}$ in $\mathrm{Y}$ such that $f(x) \in V, y \in W a n d V \cap W=\phi$. Thenint $(c l(V)) \cap \operatorname{int}(\operatorname{cl}(W))=\phi$. Since $\mathrm{f}$ is almost $\mathrm{R}^{*}$ continuous is $f^{-1}(\operatorname{int}(\operatorname{cl}(V)))$ is $\mathrm{R}^{*}$-closed set in $\mathrm{X}$ containing x. Set $U=f^{-1}(\operatorname{int}(\operatorname{cl}(V)))$, then $f(U) \subset \operatorname{int}(c l(V))$. Therefore $f(U) \cap \operatorname{int}(c l(W))=\phi$.Hence $\mathrm{G}(\mathrm{f})$ is $\mathrm{R}^{*}$-regular in $X \times Y$.

Theorem:5.4 Let $\mathrm{f}: \mathrm{X} \rightarrow \mathrm{Y}$ be a function and let $\mathrm{g}: X \rightarrow X \times Y$ be the graph function of $\mathrm{f}$, defined by $\mathrm{g}(\mathrm{x})=$ $(\mathrm{x}, \mathrm{f}(\mathrm{x}))$ for every $x \in X$. If $\mathrm{g}$ is almost contra $\mathrm{R}^{*}$-continuous function, then $\mathrm{f}$ is an almost contra $\mathrm{R}^{*}$ continuous.

Proof: Let $V \in R C(Y)$, then

$X \times V=X \times C l(\operatorname{int}(V))=C l(\operatorname{int}(X)) \times C l(\operatorname{int}(V))=C l(\operatorname{int}(X \times V))$.

Therefore, $X \times V \in R C(X \times Y)$. Since g is almost contra $\mathrm{R}^{*}$-continuous , $f^{-1}(V)=g^{-1}(X \times V) \in R^{*} O(X)$. Thus $\mathrm{f}$ is almost contra $\mathrm{R}^{*}$-continuous.

Theorem:5.5 Let $\mathrm{f}: \mathrm{X} \rightarrow \mathrm{Y}$ have a $\mathrm{R}^{*}$-regular $\mathrm{G}(\mathrm{f})$. If $\mathrm{f}$ is injective, then $\mathrm{X}$ is $\mathrm{R}^{*}-\mathrm{T}_{0}$. Proof: Let $\mathrm{x}$ and $\mathrm{y}$ be two distinct points of $\mathrm{X}$. Then $(x, f(y)) \in(X, Y)-G(f)$. Since $G(f) i s R^{*}$-regular, there exists $\mathrm{R}^{*}$-closed set $\mathrm{U}$ in $\mathrm{X}$ containing $\mathrm{x}$ and $V \in R O(Y, f(y))$ such that $f(U) \cap V=\phi$ by lemma 5.2 
and hence $U \cap f^{-1}(V)=\phi$.Therefore $y \notin U$. Thus $y \in X-U a n d x \notin o f X-U$ and X-U is R*-open set in $\mathrm{X}$. This implies that $\mathrm{X}$ is $\mathrm{R}^{*}-\mathrm{T}_{0}$.

Theorem:5.6 Let $f: X \rightarrow Y$ have a $R^{*}$-regular $G(f)$. If $f$ is surjective then $Y$ is weakly $T_{2}$.

Proof:Let $\mathrm{y}_{1}$ and $\mathrm{y}_{2}$ be two distinct points of Y. Since $\mathrm{f}$ is surjective $\mathrm{f}(\mathrm{x})=\mathrm{y}_{1}$ for some $x \in X$ and $\left(x, y_{2}\right) \in X \times Y-G(f)$. By lemma 5.2, there exists a $\mathrm{R}^{*}$-closed set $\mathrm{U}$ of $\mathrm{X}$ and $F \in R O(Y)$ such that $\left(x, y_{2}\right) \in U \times F a n d f(U) \cap F=\phi$. Hence $Y_{1} \notin o f F$ Then $\quad Y_{2} \notin o f Y-F \in R C(Y)$ and $Y_{1} \in Y-F$. This implies that $\mathrm{Y}$ is weakly $\mathrm{T}_{2}$.

\section{References}

[1]. S.P Arya and R Gupta “ On strongly continuous mappings”. Kyunpook Math ., J.14(1974), 131- 143.

[2]. C.W.Baker, On contra almost $\beta$ - continuous functions, Kochi J.Math,1:1:8,2006

[3]. S.S.Benchalli, Umadevi I Neeli and G.P.Siddapur,Almost Contra $g \delta s-$ Continuous Functions in topological Spaces,Journal of Adv. Stu. In Topology, Vol 3,No 3.2012,76-85.

[4]. Cameron D.E ,Properties of S-closed spaces,Proc.amer Math.Soc.72,1978,581-586.

[5]. J.Dontchev,Contra continuous functions and strongly S -closed spaces ,Internt J.Math.Sci.,19(1996),15 -31.

[6]. J.Dontchev and T.Noiri,Contra semi continuous functions,Mathematica Pannonica 10(2):159- 168(1999)

[7]. E.Ekici,Almost contra pre - continuous functions,Bull.Malaysian.Math.Sci.Soc. 27:53:65,2004.

[8]. E.Ekici,On contra $\pi g$-continuous functions,Chaos,Solitons and Fractals,35,(2008), 71-81.

[9]. Gangster.M and Reilly.I,More on Almost S-continuity,Indian .J.Math.1999,41:139-146.

[10]. Y.Gnanambal, On generalizes preregular closed sets in topological spaces, Indian J.Pure Appl.Math.28(1997)351-360.

[11]. Jafari.S and Noiri.T,On contra pre continuous functions,Bull.Malays.Math.Sci.Soc 2002:25:15-28.

[12]. C.Janaki and Renu Thomas, “On R*-closed sets in topological Spaces”Int. journal of Math Archive-3(8),2012,3067-3074.

[13]. C.Janaki and Renu Thomas, $\mathrm{R}^{*}$-closed maps and $\mathrm{R}^{*}$-open maps in topological Spaces.Global Research Analysis.Vol 2,issue 6 (2013)162-165.

[14]. S.I. Mahmood,On Generalized Regular Continuous Functions in Topological Spaces,Ibn Al - Haitham Journal for pure and applied science,No 3,Vol 25,377- 385,2012

[15]. N.Nagaveni, Studies on Generalization of Homeomorphisms in Topological Spaces, Ph.D Thesis Bharathiar Univ.Coimbatore, 1999.

[16]. T.Noiri and V.Popa,A unified theory on contra continuity for functions, Ann.Univ.Sci.Budapest 44(2002),115-137.

[17]. Palaniappan and K C Rao, "Regular generalized closed sets”, Kyungpook Math. J.33 (1993), 211-219

[18]. R. Parimelzhagan and N.Nagaveni “Weakly generalized closed maps" world academy of science , engineering and technology 26.2009.

[19]. Sanjay Mishra, On Regular Generalized Weakly-closed sets in Topological Spaces, Int. Journal of Math Analysis, Vol.6,(2012).no 39,1939-1952.

[20]. Singal M.K.and Singal A.R,Almost continuous mappings, Yokohama.Math. .J.16(1968)63-73.

[21]. Soundarajan T.,Weakly Hausdroff Spaces and the cardinality of topological spaces in general topology and its relation to modern analysis and algebra.III proc. Taum, conf.Kanpur(1968)Academic,Prague(1971)301-306.

[22]. R.Staum, The algebra of bounded continuous functions into a non-archiemedian field.Pacific.J.Math 50:169-185(1974)

[23]. Steen,L.A and Seeback Jr.J.A.1970,Counter examples in topology, Holt,Rinenhart and Wiston,Newyork,1970. 